\title{
Increasing ERP Implementation Success Ratio by Focusing on Data Quality \& User Participation
}

\author{
M. Rizwan Jameel Qureshi, Alnamer M. Abdulkhalaq \\ Faculty of Computing and Information Technology, King Abdulaziz University, Jeddah 21589, Saudi Arabia \\ Email: anriz@hotmail.com, alnamer90@gmail.com
}

\begin{abstract}
ERP systems projects have been spread widely across many organizations in general and small and medium enterprises (SMEs) in particular. Regrettably, failures were the results for most of the ERP implementations. As a result of that, critical failure and success factors (CFFs \& CSFs) have been identified with the help of large number of researches. Accordingly, data quality and user participation were categorized as two of the most critical factors that threaten the success of the ERP projects. In order to raise the success percentage of such projects, a data cleansing methodology and some guidelines for user participation have been proposed.
\end{abstract}

Index Terms - ERP Implementation, SMEs, CSFs, CFFs, Data Quality, User Participation.

\section{INTRODUCTION}

In recent years, the chine of countries economy relies on the existence of the Small and Medium Enterprises (SMEs). Nowadays, SMEs tend to implement ERP systems to handle their international growth. Unfortunately, ERP systems adoption projects are not easy tasks and often they crowned to fail. Thus, many researchers have taken into their shoulder the problem of identifying the Critical Success and Failure Factors (CSFs \& CFFs) that affect ERP implementation positively or negatively. One of the researches stated that data provided, parallel systems, training, testing and customization are the most critical failure factors for ERP implementation [1]. Another research has categorized the critical success factors into three main levels organizational, operational and neutral CSFs. Organizational factors include project management, business process reengineering and project team composition/team skills. Operational factor includes adequate resources, vendor's tool and data conversion. Neutral factors include interdepartmental cooperation and software customization [4]. User participation is one of the most critical success factors [3,5]. Another study concluded that the relation between vendors and their implementation partners is one of the critical failure factors that have high impact on the ERP failure [6]. However, finding out the CSFs \& CFFs and knowing them only will not ensure the success or avoid the failure of the ERP implementation. Hence, there is a strong need to provide a series of research papers in which each paper should focus on one or two CSFs or CFFs and provide methodologies to be followed in order to increase the success ratio of the ERP implementation.

This paper is further organized as follows. Section 2 covers literature review. Section 3, the problem that is taken up in this paper is stated. Section 4, the proposed data cleansing methodology and the guidelines for the user participation are explained.

\section{RELATED WORK}

ERP implementation faces many difficulties that cause its failure. These difficulties are related to different factors. Some efforts have been done regarding the identification of these factors. In the literature researchers have identified many Critical Success Factors and Critical Failure Factors.

In [1], Ashish Kr. Dixit and Om Prakash have determined eight factors affect the ERP implementation critically. These factors are data provided, parallel systems, training and testing, expectations from the ERP System, employee retention, design \& testing, customization should be less than $30 \%$ and stakeholders shall be identified in the initial phase including customers and vendors.

As in [2] the researcher has categorized the identified CFFs into three stages. First, pre-implementation stage includes the following CFFs: selection of project leader and project team, development of requirement specification, reviewing the market, evaluating different systems, vendors, resellers and consultants, and making a contract with the vendor. Second implementation stage includes the following CFFs: project management, user training, cleaning and conversion of data, testing of the system, customization of the system. Third postimplementation stage includes the following CFFs: the training of users continued, and the companies were dependent upon support from the vendor.

As in [3], critical failure factors have been classified into seven components and each component contains a set of failure factors. These components are organizational, project management, human resources, managerial, vendor \& consultants, processes and technical. Organizational component includes internal conflicts among departments and misfit between organization structure and ERP system. Project management component includes conflicts between organization and consultants, conflicts between organization and vendors and poor risk management. 
Human resources component includes inadequate employee involvement and lack of employees' morale and motivation. Managerial component includes absence of an ERP readiness assessment before project implementation and poor top management support.
Vendor \& consultant component includes poor consultants and vendors. Processes component includes poor business process reengineering. Lastly, technical component includes high rate of system customization and inaccurate data.

Table 1. Comparison of brief literature review

\begin{tabular}{|c|c|}
\hline Title of paper & Limitations \\
\hline $\begin{array}{l}\text { a study of issues affecting ERP } \\
\text { implementation in SMES [1] }\end{array}$ & $\begin{array}{l}\text { - It does not prioritize the issues } \\
\text { - It does not show which of these factors has higher or lower impact } \\
\text { - It does not specify some criteria's to give each factor a weight } \\
\text { - It does not suggest methodologies to avoid these critical issues as much as possible }\end{array}$ \\
\hline $\begin{array}{l}\text { critical issues across the ERP } \\
\text { life cycle in small-and- } \\
\text { medium-sized enterprises: } \\
\text { experiences from a multiple } \\
\text { case study [2] }\end{array}$ & $\begin{array}{l}\text { - It lacks of practical solutions helps on skipping these obstacles with minimal losses. } \\
\text { - It also should include a small survey across many SMEs that validates the criticality of the issues explored } \\
\text { from the ERP implementation experiences of five companies }\end{array}$ \\
\hline $\begin{array}{l}\text { identification and classification } \\
\text { of ERP critical failure factors } \\
\text { in Iranian industries [3] }\end{array}$ & $\begin{array}{l}\text { - The paper focused on its identification only on the Iranian industries. } \\
\text { - All the failure factors extracted cannot be considered as critical failure factors in all the countries. } \\
\text { - It also does not put a weight for each factor to show how critical this factor is. } \\
\text { - It does not provide any methodologies to avoid the most critical or the fatal failure factors. }\end{array}$ \\
\hline $\begin{array}{l}\text { critical success factors for ERP } \\
\text { implementation in SMES [4] }\end{array}$ & $\begin{array}{l}\text { - Finding out the success factors and knowing them only will not ensure the overall success of the ERP } \\
\text { implementation. } \\
\text { - The most important is that What are the methodologies that can be followed to increase the success } \\
\text { percentage of the ERP implementation? }\end{array}$ \\
\hline $\begin{array}{l}\text { enterprise resource planning } \\
\text { (ERP) system implementation: } \\
\text { a case for user participation [5] }\end{array}$ & $\begin{array}{l}\text { - It is made upon the results of its literature review of the previous work only. } \\
\text { - It does not include any other research methodology such as case study, surveys or interviews to justify its } \\
\text { conclusion. } \\
\text { - It lacks of providing more details about the user participation in different stages of the ERP implementation } \\
\text { e.g. the impact of the user participation during the testing or the training phases. }\end{array}$ \\
\hline $\begin{array}{l}\text { the impact of ERP partnership } \\
\text { formation regulations on the } \\
\text { failure of ERP } \\
\text { implementations [6] }\end{array}$ & $\begin{array}{l}\text { - This research lacks of sufficient evidence or statistics to prove its claim of the criticality of Vendor-Partners } \\
\text { relations. } \\
\text { - It concluded by reviewing one company experience. } \\
\text { - It does not classify this factor under ERP different phases. }\end{array}$ \\
\hline $\begin{array}{l}\text { identifying critical success } \\
\text { factors for ERP in SMES } \\
\text { through a case study [7] }\end{array}$ & $\begin{array}{l}\text { - This research has done the analysis for only one failed ERP system. } \\
\text { - Its results would be more efficient if it took more case studies and compare their analysis. } \\
\text { - It does not provide suggested methodologies to be followed in order to avoid the failure reasons of the } \\
\text { mentioned company. }\end{array}$ \\
\hline $\begin{array}{l}\text { a comparative study on the } \\
\text { conceptual and contextual } \\
\text { perception about CSF for ERP } \\
\text { adoption in the SMES [8] }\end{array}$ & $\begin{array}{l}\text { - The sample size used in this study was small. } \\
\text { The ranking collected from SMEs was not clearly show that who did or put this ranking? In other words } \\
\text { which of all the ERP adoption stakeholders have done the ranking? }\end{array}$ \\
\hline $\begin{array}{l}\text { ERP implementation issues } \\
\text { and challenges: a fishbone } \\
\text { analysis in context to Indian } \\
\text { industries [9] }\end{array}$ & $\begin{array}{l}\text { - I think the future work could be selecting one of these factors that has higher impact on the ERP failure and } \\
\text { dig deep in it } \\
\text { - Provide methodologies to be followed in order to raise the success impact of the selected factor. }\end{array}$ \\
\hline $\begin{array}{l}\text { critical success factors of } \\
\text { enterprise resource planning } \\
\text { implementation in small and } \\
\text { medium enterprises in } \\
\text { developing countries: a review } \\
\text { and research direction [10] }\end{array}$ & $\begin{array}{l}\text { - This paper highly depends on the previous related work results. } \\
\text { - It lakes of any scientific research methodology such as surveys or interviews. } \\
\text { - It has classified the CSFs into some importance levels without any scientific prove or statistical analysis. }\end{array}$ \\
\hline $\begin{array}{l}\text { interrelations of critical failure } \\
\text { factors in ERP implementation: } \\
\text { an ism-based analysis [11] }\end{array}$ & $\begin{array}{l}\text { - I think the future work for this paper is to take a part of the resulted hierarchy and find out, How the factors } \\
\text { are affecting each other? }\end{array}$ \\
\hline $\begin{array}{l}\text { analysis of enterprise resource } \\
\text { planning system (ERP) in } \\
\text { small and medium enterprises } \\
\text { (SME) of Malaysian } \\
\text { manufacturing sectors: current } \\
\text { status and practices [12] }\end{array}$ & $\begin{array}{l}\text { - Its study was focused on Malaysian Manufacturing sector only. } \\
\text { - I think the future work is trying to answer the following question Can we generalize the concluded results for } \\
\text { all manufacturing sector in the world? }\end{array}$ \\
\hline $\begin{array}{l}\text { factors influencing ERP } \\
\text { implementation in Indian } \\
\text { SMES: an empirical analysis } \\
{[13]}\end{array}$ & $\begin{array}{l}\text { - I think the future work for this is to select one or two factors and then dive deeply in its details to provide } \\
\text { practical and technical methodologies that increase the success percentage of that factor. }\end{array}$ \\
\hline $\begin{array}{l}\text { the dynamics of critical } \\
\text { success factors in ERP } \\
\text { implementation: an SME } \\
\text { failure case [14] }\end{array}$ & $\begin{array}{l}\text { - I think the future work for this is to start providing methodologies for SMEs to be followed when adopting } \\
\text { ERP system. }\end{array}$ \\
\hline $\begin{array}{l}\text { analysis and exploration of } \\
\text { critical success factors of ERP } \\
\text { implementation: a brief review } \\
{[15]}\end{array}$ & $\begin{array}{l}\text { - I think the future work for this is to dig deeply into the details of one these identified CSFs and start } \\
\text { methodologies for that factor to insure its success ratio. }\end{array}$ \\
\hline
\end{tabular}


The authors of [5] have taken into account the impact of the users as an impact dimension of the enterprise success measuring model. User participations can be divided into two areas: participation in the stage of definition of the organization's ERP and in the implementation of the ERP. Users are familiar with the business processes and the knowledge domain in their functional units. Thus, they should be involved in the first area to shape the system based on their priorities and business requirements in order to control the outcome. In the second area, user participation is needed to address any problems related to the compatibility of the processes and features with the organizational information needs. Also, ERP implementation may require making changes in the business processes and procedures to fully utilize it. So, users have to be involved to guide these changes to the way that benefits the organization.

As in [7], five factors that have high impact on the ERP implementation failure of the company mentioned in the case study. These factors are project management \& monitoring, top management support, competence of the project team, proper package selection \& software development and implementation strategy.

In [9], the following critical issues with the criticality percentage of each one clear scope of implementations $16 \%$, top management commitment $13 \%$, proper implementation strategy $19 \%$, vendor selections $9 \%$, project management $19 \%$, user training and education $15 \%$ and change management $9 \%$.

As mentioned in [10], the most important success factors for ERP implementation in SMEs of developing countries are business plan, clear goals \& objectives, effective education and training.

As in [11], Sanjay Jharkharia has selected nine factors for further ISM analysis. These nine factors are: lack of change management, excessive customization, dilemma of internal integration, poor understanding of business implication and requirements, poor data quality, lack of top management support, hidden cost, misalignment of IT with business and limited training. After applying the ISM analysis, the paper resulted that poor understanding of business implication and requirements, lack of top management support and poor data quality are the root of other CFFs.

The authors of [12] stated that high cost, huge consultation fees to overcome software problems and maintenance cost are major difficulties faced by the Malaysian manufacturing SMEs while implementing ERP systems. As in [13], the overall analysis concludes and prioritizes the following factors as the most influencing factors project champion, user knowledge, ERP importance, ERP team composition, interdepartmental communication, and package selection. In [14], the following factors were identified poor project management lack of strong leader, poor communication, undocumented promises \& messages, unnecessarily customizations and adjustments and bad training timing e.g. making the training in the holidays. In [15], the following critical success factors of ERP implementation were extracted top management, change management, project management, business process reengineering, IT infrastructure, communication, and user training. Table 1 gives a brief description of the literature reviewed regarding this paper including project title and some limitations which are found in them.

\section{RESEARCH PROBLEM}

There are many CSFs \& CFFs pre-identified in a lot of research papers. Two of the most important factors are: data quality and user participation $[1,3,5,11]$. For sure these factors can increase or decrease the success percentage of the ERP implementation. Therefore, maximum utilization of the positive side of the factors would be this research paper's concern. Hence, the research question that is taken up in this paper is as follows [1-5, 7, 9, 13-15].

What are the methodologies that can be followed and applied to raise the success percentage of data quality and user participation?

\section{THE PROPOSED SOLUTION}

A methodology is going to be identified carefully for the selected factors: data quality and user participation. This methodology will be formalized based on interviews with different ERP stakeholders, documents review and observations. After that, a survey will be conducted on the gathered guidelines to validate, classify and rank.

\section{A. Data Quality:}

It is considered as one of the most critical failure factors for the ERP implementation. ERP systems have special specifications to unify the data among all the different modules to insure the integrity and consistency of the database. Therefore, most of the ERP systems enforce the organization to go through data cleansing phase to ensure that all the data of the old system is consistent with the ERP specifications for further data migration phase. In order to turn this failure factor into success factor and raise its success percentage, an organization should follow the following procedures:

1. Clear Data Cleansing Strategy: organization's IT members with the ERP implementation team must have a big picture of the old system data. They should examine database size, tables, columns, data types, referential constraints between the tables, relations and so on. Furthermore, they need to apply a full comparison between the old systems data specification and the new ERP data requirements. Based on all that, they must prepare and plan clear strategy for the data cleansing phase. This strategy should address the following:

a. How much data must be cleansed?

b. The prototype system to be used for the cleansing.

c. Data operators.

d. Training procedures on the cleansing system. 
e. Following up data operators.

f. Regular reports for the status of cleansed data.

g. Time estimation to complete this task.

h. Which module to be cleansed first?

2. Organization's top management commitment: high level commitment to stick on the planned strategy and continuous following up from the top management is critically required.

3. Partial abandonment of the old system: data cleansing phase mainly focus on the historical data and the current active data. ERP projects often take long time to be fully implemented. Thus, the continuous working on the old system will cause the new data which has been processed during the implementation of the ERP to be old at the time of deploying the ERP and for sure the data will need further cleansing. So, the organization should abandon working in the old system and develop a temporary system that matches the ERP data requirements or simply use the same cleansing prototype to enter the new data. If an ERP module is ready to be used the organization should use it to ensure the new data will be $100 \%$ consistent with the other modules.

4. No outsource data operators: most of the organizations hire outsource data operators for the data cleansing phase. This is one of the critical reasons that cause delays of the data cleansing phase. Delays occur because of the time wasted by the new operators to understand the organization's business logic and to get training to use the cleansing system. Many ERP stakeholders complain that the outsource data operators are not working effectively and sincerely. They say that data operators do not understand how critical the data correction and entry is to the organization business and how a simple mistake would cause cascading effects to other related data. Additionally, outsource data operators do not have loyalty to the organization because they are working temporarily. Moreover, organizations tend to hire operators with low level education because they take fewer salaries. Therefore, a heavy work from the data validating members is required to review the work of the data operators which might require re-cleansing and revalidating.

5. Data operators should be from the organization's employees: assigning employees from the same organization to work as data operators will reduce most of the problems mentioned in the previous clause and also will make the work of the data validators easy. And that is because the organization's employees are already familiar with their business, know the importance of the data, know the data interrelations and have loyalty toward the organization.

6. Data cleansing methodology should be applied to guarantee the accuracy of the data. Fig. 1 shown below describes a suggested data cleansing methodology. This methodology requires a temporary system which should be developed for the cleansing purpose. This system is connected to two databases. The first one is the original database of the organization's old system for reading the data to be cleansed. The second one is either a temporary database, built based on the new ERP database specifications, to hold the data temporarily for further migration or it is the ERP database itself.

Level 1 (DMP) data manipulation programmatically: many of the data problems in the data cleansing phase can be solved faster programmatically. Hence, the organization should hire data manipulation professionals or simply ask the implementation team to do this. For example, removing additional spaces, special characters, spilling mistakes, texts case manipulation and many other problems can be solved by applying specific functions or SQL batches. For sure, the data manipulation

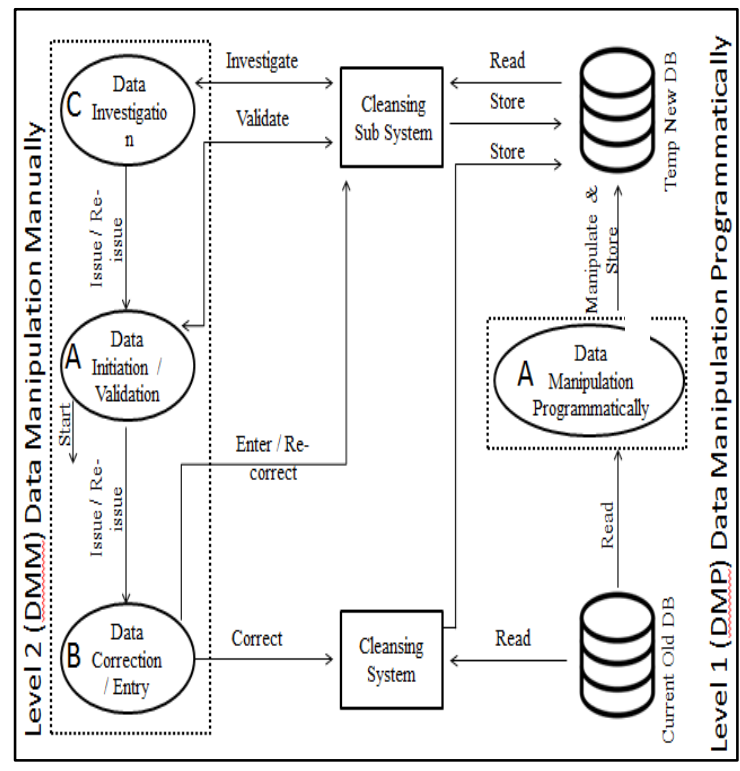

Fig. 1. (Data cleansing methodology)

programmers should be very careful when applying their procedures on the data, study the data intensively, divide the data into parts, perform the data processing on each part separately and take backups of the original data. In order to accelerate the work of these programmers in terms of studding the data and how the data should be after cleansing, they need the help of organization's employees. Thus, employees should be dedicated to work with the programmers in all the different modules of ERP system.

Level 2 (DMM) data manipulation manually: to guarantee the integrity and consistency of the data and avoid redundancy, this level has been divided into three operations described below:

a. Data initiation or validation: in this operation, group/s of employees is going to be assigned to initiate and further validate the work of the data operators (data entries). Their duty is to issue the data to be cleansed, missing data or the new data to be entered which comes from the current ongoing work of the organization. Furthermore, they have to validate the data entries work and reissue the work again if there is any need to recleanse. 
b. Data correction or entry: in this operation, group/s of employees is going to be assigned to cleanse the old data, enter missing data or enter the new data.

c. Data investigation: in this operation, group/s of key business users is going to be assigned to dig deep inside the data searching for technical or logical mistakes, errors or mismatching. In case of finding errors they issue them to the data validators who, in turn, will re-issue these errors the data entries. This operation is very important since it is considered as the final checking on the correctness of the data.

These operations work as a continuous cycle. Moreover, it is highly recommended that all the assigned employees in all the operation should be employees from the same organization as stated before.

\section{B. User Participation}

It one of the key factors affect ERP implementation. To utilize this factor positively and effectively organization should follow the guidelines below:

1. Organization IT members and key business employees should be tightly coupled with the implementation team to work throughout all the modules of the ERP system.

2. Business procedures and logic should be documented in the present of both users and implementation team. The users participate to identify the business logic and the team should understand the logic for further applying in the ERP modules.

3. Organization employees should be motivated financially and morally to participate effectively with the implementation team.

4. Group/s of employee/s should be assigned the full responsibility of each module during the implementation of the ERP system. This end up with a set of employees who are already familiar in using the ERP system. Thus, the will participate highly in the system testing phase and training phase. Their participation in the training phase will very efficient because they are already known by other employees.

5. It is highly recommended to have strong commitment from the top management to motivate the assigned employees to collaborate sincerely with the implementation team.

\section{CONCLUSION}

ERP systems adoptions have spread widely across many small and medium enterprises. Unfortunately, many ERP systems projects face critical obstacles that cause those projects to fail. Therefore, lots of researchers have carried the burden of identifying the factors that make the ERP implementation hard and end in failure. Two of the most critical failure and success factors are data quality and user participation. There is a strong need to provide methodologies to decrease the negative effects of the CFFs or to increase the positive effects of CSFs. Applying such methodologies will raise the success ratio of ERP systems projects. Thus, a well-designed data cleansing methodology has been proposed to ensure the data quality. This methodology consists of two levels DMP, data manipulating programmatically, and DMM, data manipulating manually. In DMP, data manipulating programmers should be hired. In DMM, the process of data cleansing is divided into three operations data initiation/validation, data correction/entry and data investigation. Moreover, a set of guidelines have been proposed to increase the positive effects of user participation. Furthermore, a questionnaire of 25 questions has been conducted to validate the proposed methodology. After applying a cumulative statistical analysis, $41.70 \%$ of the sample agreed with the suggested methodology, $32 \%$ strongly agreed to it, $11.52 \%$ disagreed to it, 5.94 strongly disagreed to it while $8.66 \%$ remained nominal.

\section{REFERENCES}

[1] Ashish Kr. Dixit, Om Prakash, "A Study of Issues Affecting ERP Implementation in SMEs" International Refereed Research Journal, 2011.

[2] Eli Hustad, Dag H. Olsen, "Critical Issues across the ERP Life Cycle in Small-and-Medium-Sized Enterprises: Experiences from a Multiple Case Study", CENTERIS Conference on ENTERprise Information Systems, 2013.

[3] Amin Amid, Morteza Moalagh, Ahad Zare Ravasan, "Identification and classification of ERP critical failure factors in Iranian industries", SciVerse Science Direct, 2011.

[4] M. MunirAhmad, Ruben Pinedo Cuenca, "Critical success factors for ERP implementation in SMEs", SciVerse Science Direct, 2012.

[5] Samwel Matende, Patrick Ogao, "Enterprise Resource Planning (ERP) System Implementation: A case for User participation", SciVerse Science Direct, 2013.

[6] Ahmed Elragala, Moutaz Haddara, "The Impact of ERP Partnership Formation Regulations on the Failure of ERP Implementations", ELSEVIER Science Direct, 2013.

[7] Veena Bansal, "Identifying Critical Success Factors for ERP in SMEs through a Case Study", International Journal of Future Computer and Communication, 2013.

[8] S. Vijayakumar Bharathi, Dr. Shrikant Parikh, "A Comparative Study on the Conceptual and Contextual Perception about CSF for ERP Adoption in the SMEs", Research world Journal of Arts, Science \& Commerce, 2012.

[9] Dr. Manas Kumar Sanyal, Sajal Kanti Bhadra, Sudhangsu Das, "ERP implementation issues and challenges: A FISHBONE analysis in context to Indian industries", IRACST- International Journal of Research in Management \& Technology, 2012.

[10] Majid Aarabi, Muhamad Zameri Mat Saman, Kuan Yew Wong, Hooshang M. Beheshti, Norhayati Zakuan, "Critical Success Factors of Enterprise Resource Planning Implementation in Small and Medium Enterprises in Developing Countries: a Review and Research Direction", Conference on Industrial Engineering and Service Science (IESS), 2011. 
[11] Sanjay Jharkharia, "Interrelations of Critical Failure Factors in ERP Implementation: An ISM-based Analysis", 3rd International Conference on Advanced Management Science, 2011.

[12] Yousef Khaleel, Riza Sulaiman, Nazlena Mohamed Ali, Mohd Syazwan Baharuddin, "Analysis of Enterprise Resource Planning System (ERP) in Small and Medium Enterprises (SME) of Malaysian Manufacturing Sectors: Current Status and Practices", Jurnal Teknologi Maklumat \& Multimedia, 2011.

[13] Rana Basua, Parijat Upadhyayb and Pranab k Dana, "Factors influencing ERP implementation in Indian SMEs: An empirical analysis", Management Science Letters, 2011.

[14] Eli Hustad, Dag H. Olsen, "The Dynamics of Critical Success Factors in ERP Implementation: An SME Failure Case", 9th International Conference on Enterprise Systems, Accounting and Logistics, 2012.

[15] Mohammed A. T. AlSudairi, "Analysis and Exploration of Critical Success Factors of ERP Implementation: A Brief Review", International Journal of Computer Applications, 2013.

\section{Authors' Profiles}

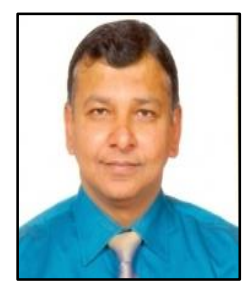

Dr. M. Rizwan Jameel Qureshi received his Ph.D. Computer Sciences degree from National College of Business Administration \& Economics, Pakistan 2009. He is the best researcher awardees of King Abdul-Aziz University Saudi Arabia in 2013 and Department of Computer Science, COMSATS Institute of Information Technology Pakistan in 2008.

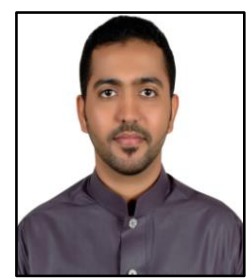

Alnamer M. Abdulkalaq received the Bachelor degree in Information Technology from King Abdulaziz University, Jeddah, Kingdom of Saudi Arabia in 2013 and currently is a Master degree student in King Abdulaziz University. Presently he is working as programmer in Netways Company, Jeddah, Kingdom of Saudi Arabia. He is having 1 year of working experience.

How to cite this paper: M. Rizwan Jameel Qureshi, Alnamer M. Abdulkhalaq,"Increasing ERP Implementation Success Ratio by Focusing on Data Quality \& User Participation", IJIEEB, vol.7, no.3, pp.20-25, 2015. DOI: 10.5815/ijieeb.2015.03.03 